\title{
АНАЛИЗ ПРИЧИН РАЗВИТИЯ ПЕРВИЧНОГО И ПОВТОРНОГО ИШЕМИЧЕСКОГО ИНСУЛЬТА
}

\author{
Дущанова Г.А., Мустапаева Г.А., Зулфикарова Э.Т.* \\ Южно-Казахстанская государственная фармацевтическая академия, кафедра неврологии, пси- \\ хиатрии и психологии, Шымкент, Республика Казахстан
}

\begin{abstract}
Церебральный инсульт является значимой клинической, социальной и экономической проблемой. Повторный ишемический инсульт достоверно усугубляет инвалидизацию больных, преимущественно за счет развития более грубых двигательных нарушении гетерогенного характера (как пирамидных, так и подкорковых) и когнитивных нарушений, достигающих степени деменции, а также приводит к более продолжительной госпитализации. Больные с повторным ишемическим инсультом характеризуются частым сочетанием цереброваскулярной патологии с другими поражениями сердечно- сосудистой системы и распространенным атеросклерозом. Наличие инвалидизации после первого инсульта обуславливает снижение адаптационных способностей организма и создает предпосылки для гемореологических и метаболических нарушений, а также персистирования хронической инфекции.

Ключевые слова: ишемический инсульт, вторичная профилактика, факторы риска.
\end{abstract}

Церебральный инсульт является значимой клинической, социальной и экономической проблемой. Значительное увеличение удельного веса лиц пожилого и старческого возраста в общей структуре населения в странах с высоким экономическим потенциалом существенно влияет на все уровни организации общества, что требует глубокого изучения особенностей развития, течения, профилактики и лечения сосудистых заболеваний. По данным ВО3 инсульт занимает 2 место в структуре общей смертности, и первое место как причина стойкой утраты трудоспособности [1]. Ежегодно в Республике Казахстан происходит свыше 49000 инсультов - заболевания, являющегося лидером по причинам смертности населения во всем мире. 80\% из всех пациентов, перенесших инсульт, навсегда остаются инвалидами. К наиболее частым последствиям инсульта относят развитие двигательных расстройств (до 80\%) и когнитивных нарушений (40-70\%), в значительной степени снижающих качество жизни пациентов. Особого внимания заслуживает профилактика повторного нарушения мозгового кровообращения [2,3]. Пациенты, ранее перенесшие нарушение мозгового кровообращения; имеют в 6 раз выше риск развития повторного инсульта, нежели люди такого же пола и возраста, ранее не имевшие такового [4-7]. По разным данным в течение первого года у 4 $17 \%$ пациентов повторно развивается ишемия *e-mail: ellichka.zh@mail.ru головного мозга [8]. Частота повторных инфарктов мозга колеблется в разных регионах от $20 \%$ до $40 \%$ в год и является самой высокой в мире [9]. Многочисленные исследования, проводимые в мире, прежде всего, направлены на усовершенствование методов первичной профилактики инсульта, предупреждение повторных ИИ во многом базируется на исследованиях, посвященных успешной профилактике первичных инсультов [10,11].

Цель исследования: сравнительный анализ причин развития инсульта у больных с повторным и с впервые развившимся ишемическим инсультом.

Материал и методы исследования. Работа проводилась на базе нейрососудистого отделения Областной клинической больницы г. Шымкента. Отбор проводился среди пациентов, находящихся под наблюдением в поликлинике областной клинической больницы. В исследование включались мужчины и женщины старше 65 лет, с диагнозом ишемический инсульт, наличие которого - можно было подтвердить при изучении истории болезни (жалоб, анамнеза, результатов врачебного осмотра, инструментальных исследований - КТ и МРТ - исследования), независимо от патогенетического механизма развития и клинической выраженности заболевания. Критерии исключения: геморрагический инсульт, онкологическое, воспалительное и очаговое нейродегенеративного поражение головного 
мозга.

Согласно данным НИИ Неврологии РАМН выделяют следующие патогенетические подтипы: атеротромботический (АИИ), кардиоэмболический (КИИ), гемодинамический (ГИИ), лакунарный инсульт (ЛИИ) и инсульт по типу гемореологической микрооккюзии. Была выделена категория больных с неустановленным ведущим патогенетическим механизмом (НИИ), куда относили пациентов с конкурентной патологией.

После отбора в исследование были включены 102 больных с ишемическим инсультом, отвечающих вышеперечисленным критериям, среди них 38 (37,3\%), мужчин и 64 (62,7\%) женщин. Более $80 \%$ больных были старше 70 лет. Средний возраст больных составил 76,98 лет. В период госпитализации умерло 48 $(47,1 \%)$ больных. Основную группу составили пациенты с повторным ИИ - 51 больных $(50,0 \%)$. Группу сравнения составили 51 больной сопоставимых по группам, в зависимости от пола и возраста.

Больным, включенным в исследование, проводился тщательной сбор анамнеза, анализ медицинской документации, обследование неврологического и общесоматического состояния. Оценивались очаговая неврологическая симптоматика, измерялись пульс и артериальное давление, температуры тела, проводились аускультация легких. Для проведения дифференциального диагноза и уточнения характера симптомов привлекались консультанты - врачи, смежных клинических специальности.

Неврологический статус оценивался по шкале института национального института здоровья (National Institules of Health (NIH) Stroke Scale-NIHSS). Шкала содержит 15 пунктов, которые характеризуют основные функции, чаще всего нарушающиеся вследствие инсульта. Оценка производится в баллах. Шкала имеет очевидную лицевую валидность, внутреннюю согласованность и ретестовую надежность [11]. Неврологический статус оценивался при поступлении больного в стационар и спустя 3 недели.

Для оценки когнитивных функций исполь- зовалась Краткая шкала психического статуca - MMSE (от англ. Mini Mental State Examination). Результат теста равный или менее 24 баллов оценивался как угроза развития деменции [12]. Выше 24 баллов - у больного имеются когнитивные нарушения легкой или умеренной степени. Диагноз деменции считался подтвержденным, если когнитивные нарушения сохранялись на протяжении 6 месяцев после повторного инсульта и в случае смерти больного при отсутствии положительной динамики когнитивных нарушений в течение данного времени. У больных после первого инсульта диагностировались деменция также спустя 6 месяцев на амбулаторном этапе.

Исход инсульта оценивался шкалой Рэнкин (J.Rankin, 1957. D.Wade, 1992), которая содержит 5 степеней нарушения жизнедеятельности.

Источником информации о первом инсульте служили архивные истории болезни и данные амбулаторной карты пациента. Информация о степени самообслуживания уточнялись родственниками больного.

Методы лабораторно-инструментального обследования больных: электрокардиография, лабораторные методы исследования, рентгенологические исследование, нейровизуализационные методы исследования, компьютерное томографическое (КТ) исследование проводилось всем пациентам с подозрением на инсульт, магнитно - резонансная томография (МРТ) назначалась при локализации ишемического инсульта в задней черепной ямке, в случаях ухудшения клинического течения, допплерография сосудов головного мозга (ДГСГМ).

Результаты исследований. Надо отметить, что все пациенты в исследовании имели кардиопатологию: все пациенты с повторным инсультом страдали ИБС, в группе сравнения (пациенты с первым инсультом), за исключением 1 больного, также имели ИБС (97\%). Достоверные различия достигнуты в распределении больных по степени выраженности стенокардии напряжения (рис. 1). 


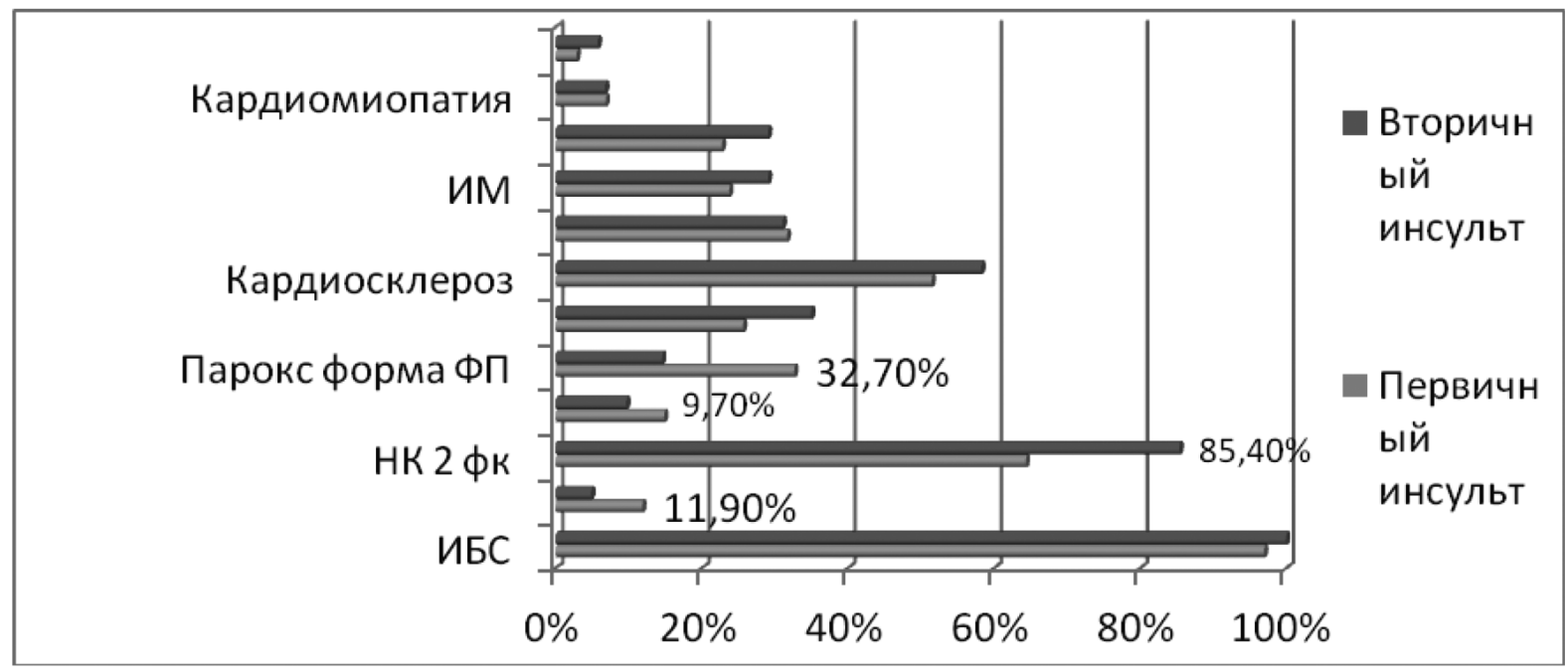

Рис. 1. Основные кардиальные факторы риска у госпитализированных больных с ишемическим инсультом, $* * * \mathbf{p}<0,001 ; * * \mathbf{p}<0,05 ; * \mathbf{p}<0,01$

Большинство пациентов обеих групп 77 (75\%) больных) имели стенокардию напряжения 2 ФК. В группе контроля таких пациентов было меньше $(64,4 \%$, против $85,4 \%)$, из них четверть пациентов не имели клинических проявлений стенокардии напряжения или имели начальные симптомы $(11,9 \%)$ и напротив были больные с выраженными проявлениями стенокардии (14,9\% и 9,7\% - в основной группе). Основным фактором риска кардиоэмболического инсульта является нарушение ритма сердца (фибрилляция предсердий). Среди больных с мерцательной аритмией (пароксизмальная и постоянная форма) выявлены достоверные отличия, в частности, в преобладании пароксизмальной формы ФП среди пациентов группы сравнения (в основной $14,6 \%$ и в контрольной $32,7 \%$ ). Нарушение проводимости чаще встречалось у пациентов с повторным инсультом. Вдвое больше больных имели ревматизм с формированием приобретенного порока сердца среди пациентов с повторным инсультом 3 (5,8\%) пациентов - в основной группе и 1 (2,9\%) - в группе сравнения).

Основными анализируемыми факторами риска повторного инсульта является АГ, НК, СД. Среди пациентов с повторным инсультом $83,5 \%$ больных страдали АГ, из них 24,3\% имели 3 стадию заболевания, что в два раза выше, чем среди пациентов контрольной группы (11,9\%). Достоверные отличия выявлены в проявлении НК - 98,1\% больных с повторным инсультом имели недостаточность кровообращения, преимущественно 2 стадию (70,9\%). Это отличало их от группы сравнения, в которой 75,3\% имели недостаточность кровообращения, из которых 33,7\% имели 1 стадию. Пациентов страдающих 1 типом СД было одинаковое количество - по 2 больных, в тоже время больные с сахарным диабетом превышали в группе с повторным инсультом (31,1\%, против 18,8\% больных). Практически вдвое чаще у больных с повторным инсультом находили, при обследовании, облитерирующий атеросклероз $26(50,5 \%)$ и $16(30,7 \%)$ - в группе сравнения ( $\mathrm{p}=0,003)$. Большее количество больных с вторичном инсультом страдали варикозной болезнью нижних конечностей $32(63,1 \%)$ и $25(48,5 \%)$ в контрольной группе.

Основными факторами ишемического инсульта, относящиеся к факторам образа жизни, является ожирение и курение. В исследуемых группах данные различия достигли достоверности. Ожирением страдали преимущественно пациенты с повторным инсультом - 30,1\% (в группе контроля - 17,8\%), чаще являлись курильщиками - 17 (33,7\%), в группе сравнения - 10 (19,4\%) больных.

Одним из критериев при постановке атеротромботического инсульта является наличие атеросклеротических бляшек в каротид- 
ных артериях. При амбулаторном исследовании незадолго до инсульта (в течение полугода до поступления с инсультом) некоторым пациентам было проведено ЦДС магистральных артерий шеи (22 больным, которые впос- ледствии перенесли повторный инсульт и 20 пациентам - у которые впоследствии поступили с первые возникшим инсультом). В рис. 2, представлены результаты исследования ДССГМ данных больных.

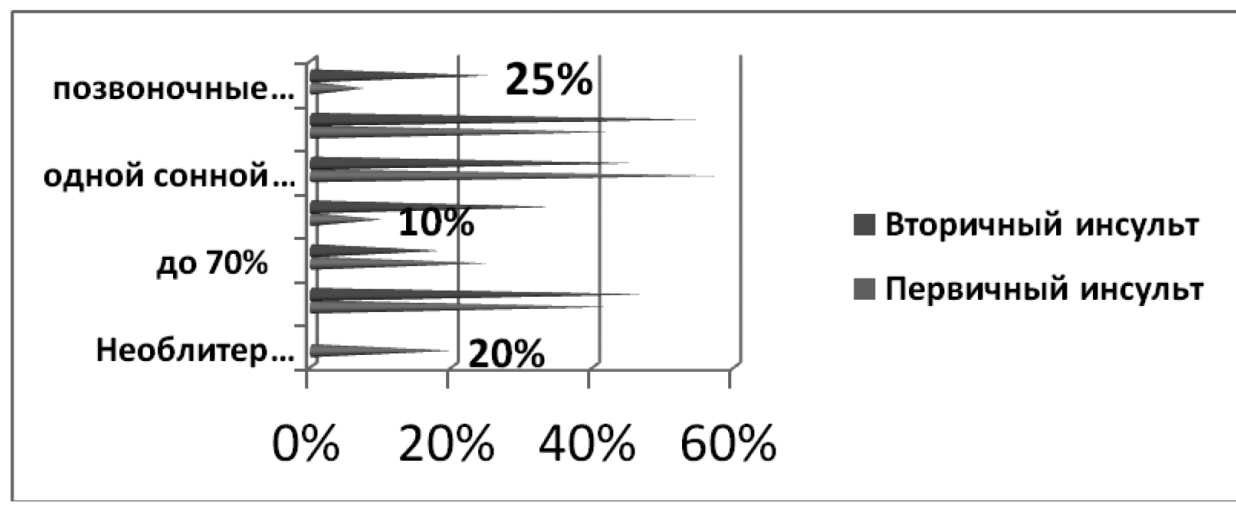

Рис. 2. Результаты допплерографии сосудов головного мозга у исследуемых больных ***p<0,001; **p<0,05; *p<0,01 Вероятность (Р) оценивалась с помощью критерия значимости Реarson х2 и Fisher's Exect tests.

При допплерографии сосудов выявлены достоверные различия между двумя группами. У больных с повторным инсультом выявляется поражение каротидных артерий, которые носят значительно выраженный характер по сравнению с больными контрольной группы. У больных, перенесших повторный инсульт практически в 4 раза чаще выявляется крайняя степень выраженности атеросклероза - полная окклюзия сонной артерии. При исследовании позвоночных артерии выявляются достоверное различия: больные с повторным инсультом чаще имеют поражение позвоночных ар- терий - 25\% больных и в группе сравнения у 7,5\% больных. Надо отметить, что поражение позвоночных артерий при исследовании было не только в результате атеросклероза, но и дегенеративных изменений позвоночника (остеохондроз шейного отдела позвоночника).

Основные сопутствующие заболевания представлены в рис. 3. Хронический бронхит и ХОБЛ встречалась у 64,1\% больных с повторным инсультом и 77,2\% в контрольной группе. Бронхиальная астма была у $5(8,9 \%)$ больных с повторным инсультом и 3 (6,8\%) больных в группе сравнения.

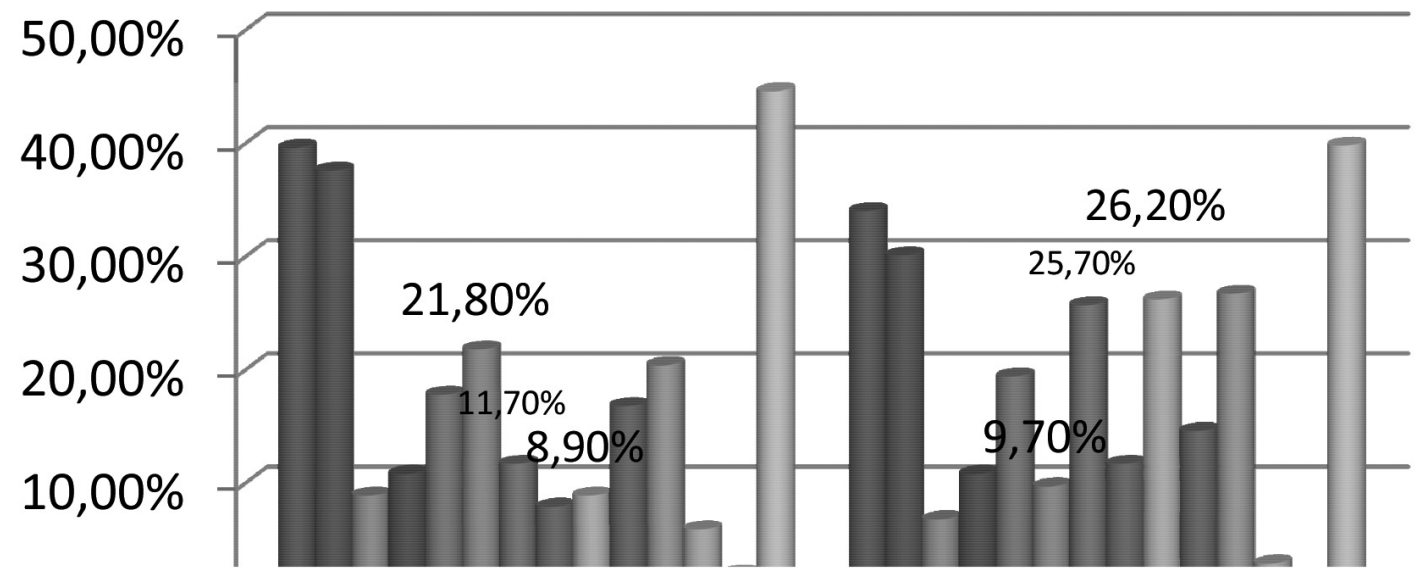

Рис. 3. Частота сопутствующих заболеваний у госпитализированных больных с ишемическими инсультом *** - p<0,001; ** p<0,05; *-p<0,01 Вероятность (Р) оценивалась с помощью критерия значимости Реагson х2 и Fisher's Exect tests. 
Патология щитовидной железы (в основном, гипотиреоз) была выявлена в $11,7 \%$ случаев у пациентов с повторным инсультом и 7,9\% у пациентов контрольной группы пациентов контрольной группы. В группе контроля у 1 (1,9\% больных) выявлялся туберкулез, в неактивной фазе, в основной группе данной патологии не выявлено. Среди неврологических заболеваний наиболее часто встречались подкорковые нарушения, которые преобладали у больных с повторным инсультом $14(26,7 \%)$ и у $10(20,4 \%)$ в контрольной группе, данные различия не достигли статистической достоверности. Надо отметить, что у пациентов с повторным инсультом, паркинсонизм носил характер синдрома в результате церебрально - сосудистых нарушений. Обращает внимание достоверное увеличение частоты встречаемости остеоартроза у больных с повторным инсультом 13 (26,2\%) больных в анализируемой группе, против 4 $(8,9 \%)$ - в контрольной. Хроническая почечная недостаточность выявлялась более чем в 2 раза чаще в группе сравнения - $11(21,8 \%)$, по сравнению с $5(9,7 \%)$ случаями основной группы. Также достоверно отмечено преобладание ЖКБ и хронического холецистита в группе сравнения - $6(11,7 \%)$ и у больных с повторным инсультом - 13 (25,7\%).
Социальная значимость инсульта определяется, прежде всего, последствиями инсульта, основными из которых - высокая смертность и инвалидизация. Нарушение двигательных функций и когнитивных нарушений обуславливают степень инвалидизации, $37,8 \%$ - вторую степень, девять больных $(8,7 \%)$ - третью степень и один больной 4 степень.

Степень инвалидизации у обследуемых больных определялась синдромокомплексом преимущественно когнитивных и двигательных расстройств. Легкие когнитивные нарушения присутствовали у 35,9\% больных и 9,7\% больных имели деменцию. Психические нарушения присутствовали у 10,6\% больных. Эпилептический синдром развился после инсульта у 8,7\% больных. Речевые расстройства обнаруживались у 12,6\% больных. Треть больных имели нарушение двигательной активности, обусловленное пирамидной слабостью. Легкий парез выявлялся у 11 (22,3\%) больных, грубый пирамидный дефект у 6,7\%. Атактическими расстройствами страдали 5,8\% больных, у 24,2\% больных имело место различной степени выраженности экстрапирамидные расстройства. В рис. 4. представлены клинические последствия ранее перенесенного ишемического инсульта.

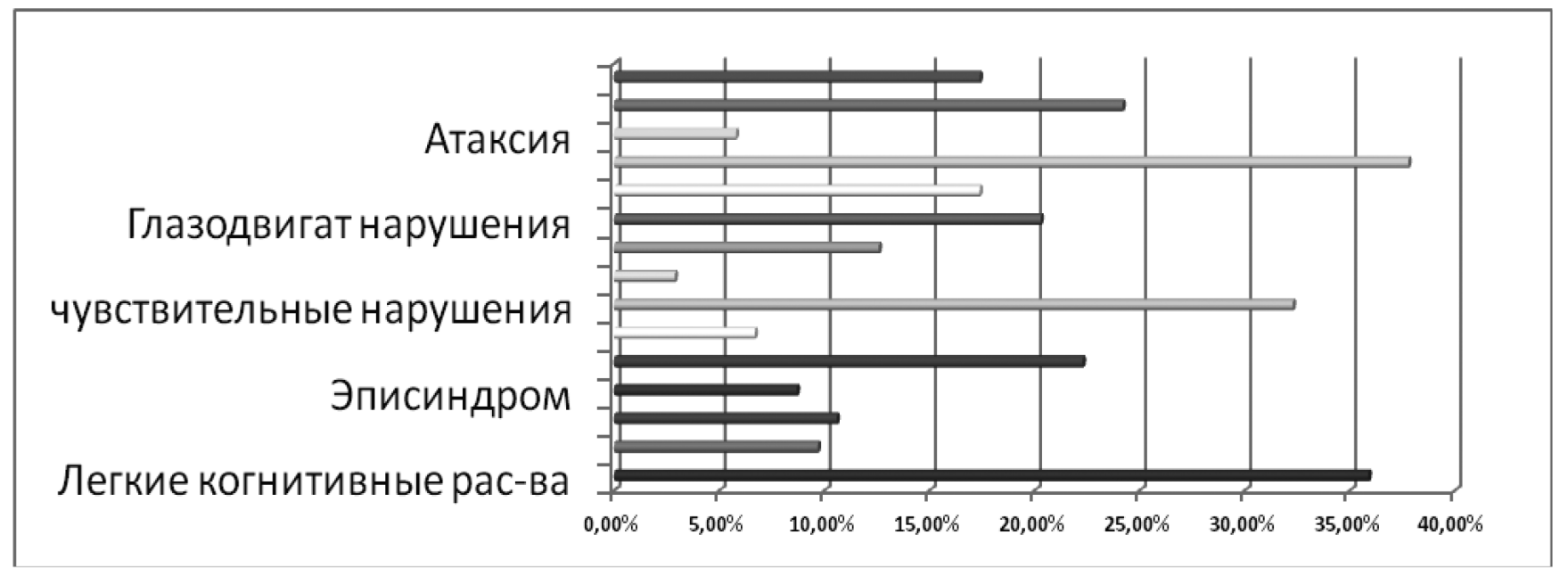

Рис. 4. Клинические последствия ранее перенесенного инсульта у больных с повторным инсультом.

Более ранние исследования показали роль повторного инсульта в усугублении инвалидизации [12-14]. В нашем исследовании, среди
27 больных, выживших после повторного инсульта, так же отмечено повышение степени социальной и физической зависимости боль- 
ных. В рис. 5, представлена частота неврологических знаков до и после повторного инсульта среди выживших больных.

Если до повторного инсульта 17,1\% больных не имели остаточных симптомов, и не было больных с глубокой степенью инвалидизации, то после перенесенного повторного инсульта все больные имеют ту или иную степень зависимости, из которых $38,8 \%$ стали нуждаться в постоянном уходе.

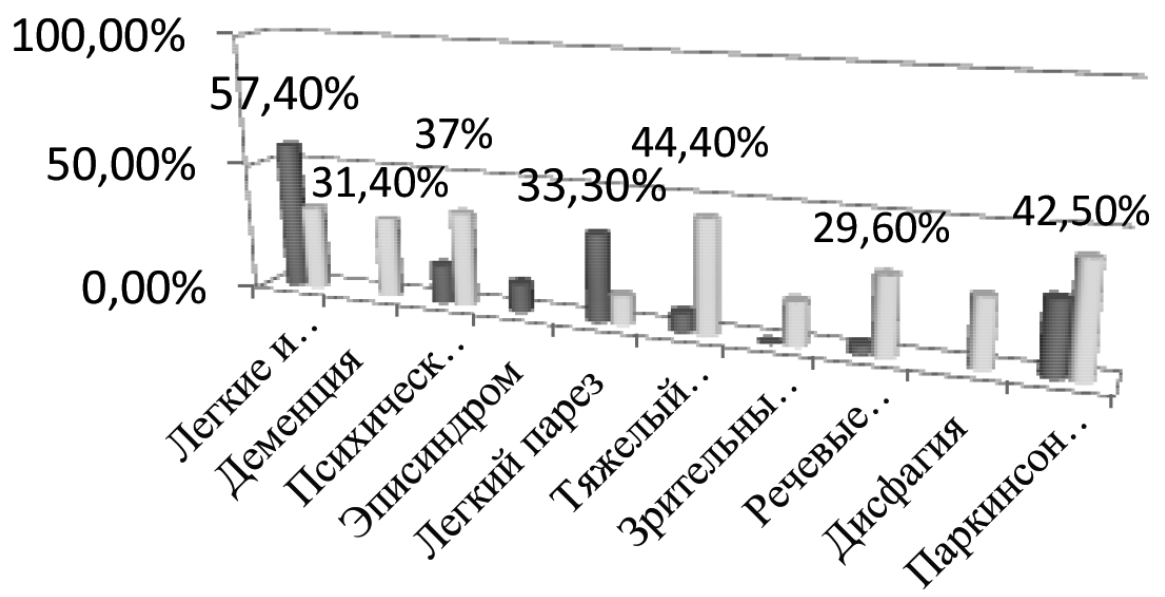

п До повторного инсульта

После повторного инсульта

Рис. 5. Характеристика неврологических нарушений до и после повторного инсульта у выживших больных ***p<0,001; **p<0,05; *p<0,01 Вероятность (Р) для качественных признаков оценивалась с помощью критерия значимости Pearson.

Таким образом, повторный инсульт приводит к выраженной инвалидизации больных. Усиливается когнитивная дисфункция на фоне усугубления психических и двигательных нарушений гетерогенного характера (сочетание пирамидных, координаторных и подкорковых нарушений).

Обсуждение. Сравнительный анализ факторов риска ИИ у больных с первым и повторным инсультом показал высокую распространенность сердечно-сосудистой патологии. При этом обращает на себя внимание более низкая частота крайней степени выраженности течения ИБС, недостаточностей кровообращения и нарушений ритма у больных в группе повторного инсульта. При этом больным данной группы более свойственно патология периферических артериальных и венозных сосудов, наличие сахарного диабета 2 типа, ожирения и курения. Надо отметить, что больные с повторным инсультом достоверно чаще страдают остеоартрозом, подкорковыми нарушениями паркинсоноподобного типа, что может быть объяснено последствием ранее перенесенного инсульта, когда нарушение морфологической структуры головного мозга приводит к формированию паркинсоноподобного синдромокомплекса. Развитие остеоартроза, застойных явлений желчи с формированием холецистита может быть обусловлено ограничением жизнедеятельности и снижением активности висцеральных рефлексов. Анализ кардиальной патологии показал, что все больные обеих групп имели кардиальную патологию (ИБС в сочетании- с различными видами нарушения ритма, и проводимости), треть больных, перенесла ИМ, при этом в группе контроля чаще встречалось бессимптомное течение инсульта. Достоверные различия обнаружены в выраженности проявления ИБС и наличии ФП. В исследуемой группе больные чаще страдали стенокардией напряжения, в сравнении с контрольной группой, где встречались как легкие, так и более тяжелые формы ИБС. Данные различия могут быть обусловлены отсутствием у ряда больных физической нагрузки, вследствие ограничения двигательной активности; что не являлось ограничительным- фактором в контрольной группе. Частая регистрация пароксизмальной формы ФП при пер- 
вом инсульте обусловлено высоким риском развития инсульта у больных данной категории, который возникает при смене ритма. Тяжелое течение и высокая, смертность в результате кардиоэмболического инсульта приводит, к уменьшению больных с повторным инсультом и соответственно частоты встречаемости пароксизмальной формы ФП.

Среди сосудистых, факторов у больных с повторным - инсультом, обращает внимание достоверно - высокая распространенность облитерирующего атеросклероза, варикозной болезни нижних конечностей, сахарного диабета 2 типа, что может свидетельствовать о многофакторном поражении сосудистого русла. Развитие варикозной болезни нижних конечностей: может быть обусловлено тем, что после перенесенного инсульта резко снижается - физическая: нагрузка, что приводит к венозному застою, появляются условия дальнейшего прогрессирования заболевания.

Анализ сопутствующей соматической патологии показал высокую встречаемость у больных с повторным инсультом остеоартроза, хронического холецистита и ожирения что может быть следствием ограничения двигательного режима и объема движений и суставах на фоне изменения мышечного тонуса, уменьшения проприорецептивной импульсации, выключения регуляторных моторно-висцеральных- рефлексов.

Допплерография сосудов головного мозга подтверждает клинические данные о более выраженном атеросклеротическом поражении сосудов у больные с повторным инсультом, у которых проявления, атеросклероза регистрировались достоверно чаще; как но степени стеноза, так и по распространенности.

Одним из определяющих факторов является степень инвалидизации с изменениями когнитивных функций, чем выраженнее социальная дезадаптация и грубее нарушены когнитивные функции, тем раньше развивался повторный инсульт. Несмотря на полиморфность заболеваний, необходимо проводить регулярный мониторинг и оценивать весомость каждого фактора риска, развития инсульта и с учетом этого проводить, как неспецифическую профилактику инсульта, так и прежде всего; коррекцию сопутствующих заболеваний.

Безусловно, развитие повторного инсульта ведет к усугублению неврологического дефекта и стойким нарушениям жизнедеятельности как социально-бытовой, так и физиологической. Отобранные больные для проведения данного исследования, как правило, были пожилого и старческого возраста, практических все больше имеют сочетания заболеваний, которые независимо друг от друга могут осложниться инсультами, но в совокупности значительно повышают риск развития инсульта. Это дает повод для определения мероприятия по вторичной профилактике инсульта с позиции патокинеза, который характеризует особенности развития и динамики патологического процесса, все его стадии и формы, клинические и морфологические варианты, а также защитно-компеисаторные механизмы, проявляющиеся в процессе болезни. В то время как патогенез определяет только характер и локализацию патологического процесса.

Выводы. Повторный ишемический инсульт достоверно усугубляет инвалидизацию больных, преимущественно за счет развития более грубых двигательных нарушений гетерогенного характера (как пирамидных, так и подкорковых) и когнитивных нарушений, достигающих степени деменции, а также приводит к более продолжительной госпитализации. Больные с повторным ишемическим инсультом характеризуются частым сочетанием цереброваскулярной патологии с другими поражениями сердечно- сосудистой системы и распространенным атеросклерозом. Наличие инвалидизации после первого инсульта обуславливает снижение адаптационных способностей организма и создает предпосылки для гемореологических и метаболических нарушений, а также персистирования хронической инфекции. 


\section{ЛИТЕРАТУРА}

1. Верещагин Н.В., Суслина 3.А., Гераскин Л.А., Фонякин А.В. Антигипергензивная терапия при сосудистой патологии мозга: успехи, спорные и нерешенные вопросы. // Кремлевская медицина. Клинический вестник.- 2003. - №2. - С.7-10

2. Гусев Е.И., Скворцова В.И. Ишемия головного мозга.- М.: Медицина, 2001.-328 с.

3. Дущанова Г.А, Профилактика нарушений мозгового кровообращения В кн: Актуальные проблемы медицины - Шымкент, 1996 с. 124.

4. Дущанова Г.А, Современные факторы риска сосудистых заболеваний мозга. В журн: Вестник академии N1, 1998 с. $25-28$.

5. Дущанова Г.А., Бейсетаева Ж.О.Результаты регистра мозгового инсульта в г. Шымкенте Материалы (статьи и тезисы) международной научно-практической конференции "Проблемы клинической и теоретической медицины", посвященной 15-летию Международного казахско-турецкого университета им. Х.А. Ясави и 30-летию клиники университета. Шымкент, 2007 г. С. 84-89.

6. Инсульт: практическое руководство для ведения больных Ч.П. Ворлоу, М.С.Деннис, >IC Вап Гейн и др.; Пер. с англ. - СПб.: Политехника, 2008.- с. 434.

7. Кадыков А.С., Шахпоронова Н.В,, Шведкой В,В. Больной, перенесший ишемический инсульт на амбу- латорном лечении // Неврология. - 2002. -1:2. - С.34-35 8. Методические рекомендации по определению показаний и противопоказаний к каротидной эндартерэктомии//Д.Н. Джибалддзе, Н.В. Добжапский и другие.; под. ред. Верещагин Н.В. - М.: НИИ неврологии PAMH, 2001.

9. Парфенов В,А. Профилактика повторного ишемического инсульта// Consilium Medicum.- 2004. - Том 6,№ 2.- СЛ3-16

10. Скворцова В.И. Медицинская я социальная, значимость проблемы инсульта/Лаолезни нервной системы. - 2004. - №4. - C.34

11. Шкалы, тесты и опросники в медицинской реабилитации: под ред. А.Н. Беловой, О.Н. Щепетовой.М.:Антидор, 2002.- 205 с.

12. Adams Bendixen B ., KappelleL. etal: Classification of subtype of acute ischemic stroke: Definitions for use in a multicenter clinical trial; TOAST. Trial of Org 10172 in Acute Stroke Treatment/ZStroke. - 1993: - Vol 24. - P. 35-4 13. Barnett H, Taylor D, Eliasziw M, et al: Benefit of carotid endarterectomy in patients with symptomatic moderate or severe stcnosisZ/N.Hngl.J.Med. - 1998. - Vol339.P. 1415-142

14. European Stroke Council. Pan European Consensus Meeting on Stroke Management, Helsingborg, Sweden: WorldFIealth Organization, 1995.-p. 35

\title{
XÜLASə
}

\section{ILKIN Və TəKRAR İŞEMIK İNSULTUN İNKIŞAF SəBəBLəRININ ANALIZİ}

\author{
Duşanova Q.A., Mustapayeva Q.A., Zulfikarova E.T. \\ Cənubi-Qazaxıstan dövlat farmasevtik akademiya, nevrologiya, psixiatriya və psixologiya kafedrası, \\ Simkənd, Qazaxistan
}

Serebral insult əhəmiyyət kəsb edən klinik, sosial və iqtisadi problemdir. Təkrar işemik insult xəstənin əlilliyini daha kobud heterogen xarakterli hərəki pozulmaların (həm piramid, həm də qabıqaltı) və demensiya vəziyyətinə qədər inkişaf edən koqnitiv pozulmaların hesabına əhəmiyyətli dərəcədə artıtır, həm də daha uzunmüddətli hospitalizasiyaya səbəb olur. Təkrar işemik insultlu xəstələrdə çox vaxt serebrovaskulyar patologiyalar digər ürək-damar sistemi xəstəlikləri və yayılmış ateroskleroz ilə müştərəkliyi ilə xarakterizə olunur. Birincili insultdan sonra əlilliyin olması orqanizmin adaptasiya qabiliyyətinin azalmasına səbəb olur və hemoreoloji və metabolik pozulmalar üçün, həm də xroniki infeksiyaların persistəetməsini şərait yaradır Açar sözlər: işemik insult, ikincili profilaktika, risk amilləri. 


\section{SUMMARY}

\section{ANALYSIS OF DEVELOPMENT PRIMARY AND REPEATED ISCHEMIC STROKE}

Duschanova G.A., Mustapaeva G.A., Zulfikarova E.T.

South Kazakhstan State Pharmaceutical Academy, department of neurology, psychiatry and psychology, Shymkent, Kazakhstan

Stroke is an important clinical, social and economic problem. Recurrent ischemic stroke significantly exacerbates disability of patients, mainly due to the development of gross motor disorders more heterogeneous nature (as pyramidal and subcortical) and cognitive impairment, due to dementia, as well as lead to a longer hospital stay. Patients with recurrent ischemic stroke are characterized by the frequent combination of cerebrovascular disease with other lesions of the cardiovascular system and widespread atherosclerosis. The presence of disability after the first stroke, leads to decrease in adaptive abilities of the organism and create prerequisites for hemorheologic and metabolic disturbances, as well as the persistence of chronic infection.

Keywords: ischemic stroke, secondary prevention, risk factors.

Redaksiyaya daxil olub: 02.11.2015

Çapa tövsiya olunub: 16.11.2015

Rayçi: t.e.d. Hasanov R.L. 